\title{
Differential Object Marking in Kazakh: The Dynamic Syntax Approach
}

\author{
Nadezda Christopher ${ }^{1}$
}

Accepted: 25 March 2021 / Published online: 24 April 2021

(c) The Author(s) 2021

\begin{abstract}
This paper presents a novel, Dynamic Syntax-based approach to the phenomenon of differential object marking in Kazakh, which can be extended at least to other Turkic languages displaying this phenomenon. It is demonstrated that the difference in the pragmatics associated with marked and unmarked direct objects, as well as the syntactic restrictions on the positioning of unmarked direct objects, can be elegantly and succinctly explicated through the application of the notions of fixed and unfixed nodes, without the need for proposing special syntactic positions or additional pragmatics for the accusative case.
\end{abstract}

Keywords Dynamic Syntax · Syntax Morphology · Differential object marking · Incorporation $\cdot$ Kazakh $\cdot$ Turkic $\cdot$ Turkish

\section{Introduction}

Differential object marking (DOM) is a phenomenon characteristic of most Turkic languages, as well as many other languages of the world. DOM in Kazakh (Kipchak, Turkic) is a representative example of Turkic DOM, and this paper provides the first formal syntactic analysis of this phenomenon employing the syntactic framework of Dynamic Syntax (DS) (Cann et al. 2005; Kempson et al. 2001). Unlike previous analyses of Turkic DOM, the proposed analysis relies exclusively on the dynamicity of the parsing process, and does not posit any association of marked or unmarked direct objects with arbitrary features or particular positions within hierarchical trees.

It is demonstrated that the accusative case marker is solely the marker of directobjecthood, and that the specificity reading pertinent to some accusatively marked direct objects is a pragmatic effect arising from the contrast in the parsing of noncase-marked and case marked direct objects. The parsing of non-case-marked direct objects is associated with structural uncertainty which is only resolved after the

Nadezda Christopher

n.christopher@surrey.ac.uk

1 University of Surrey, Guildford, UK 
predicate is parsed, while the accusative case marker resolves this structural uncertainty before the parser reaches the verb.

The DS formalism is also employed to provide a straightforward explication of the restriction of non-case-marked direct objects to the immediately preverbal position (IPV). It is shown that the IPV position is the only position within a clause where an unmarked direct object (initially parsed onto an unfixed node) is guaranteed to acquire a fixed position at the next step of the parsing process; the importance of this is discussed in Sect. 4.3.

Another important outcome of the proposed DS analysis is the observation that the Kazakh language does not allow truly unmarked noun phrases, and that each noun phrase is marked by a case marker or prosody in one of four ways: only by a case marker; only by an intonation phrase (IP) boundary; by both a case marker and an IP boundary; ${ }^{1}$ by the lack of either a case marker or an IP boundary (indicating that the noun phrase at hand is to obtain a fixed position after the predicate is parsed). The term 'unmarked' is used in this paper descriptively to denote noncase-marked arguments; where this term is used in relation to a direct object, it also implies that there is no IP boundary between that direct object and the predicate.

This paper proceeds as follows: Sect. 2 introduces the phenomenon of DOM, and provides a description of DOM in Kazakh. Since no detailed analyses of Kazakh DOM have been proposed in the literature to date, Sect. 3 outlines the main points of the previous analyses of Turkish DOM which follows the same patterns as Kazakh DOM. Section 4 focuses on the DS analysis of Kazakh DOM, which succinctly accounts for both the additional pragmatic meaning of specificity associated with some accusatively marked direct objects, and for the special nature of the IPV position; this section also presents the extensions and the constraints of the proposed analysis. Section 5 concludes this paper.

\section{Differential Object Marking: The Description}

The phenomenon of DOM is an instance of a wider phenomenon of differential case marking (DCM) or differential argument marking, which is known as case alternation and case diathesis. DCM phenomena are observed in many languages of the world, where non-uniform marking of terms is present. 'Dative alternation' in English is one example of DCM:

Julia gave a book to Mariam.

Julia gave Mariam a book.

The goal argument in (1) is marked by the preposition to and realised after the theme argument, while in (2), the same goal argument precedes the theme and is

\footnotetext{
1 Due to space limitations, this type of marking is not considered in detail, but it is relevant for the sentence initial direct object in sentences like that in (10), for instance.
} 
unmarked. These alternations have been observed to yield a difference in interpretation albeit quite a subtle one in the English language.

Bossong (1992) is attributed with coining the term 'differential object marking'; three types of this phenomenon have been identified in the literature: direct objects marked with different cases; presence/absence of agreement with direct objects on the verb; and the unmarked/marked direct object alternations. Witzlack-Makarevich and Seržant (2018) label the first type of DOM 'symmetric', and the latter two 'asymmetric'.

Only the last type of DOM is observed in Kazakh and many other Turkic languages where direct objects can appear in the IPV position either marked with the accusative case suffix or not marked with a case suffix; they are obligatorily casemarked outside of the IPV position. The Turkish examples in (3), (4), and (5) demonstrate this.

(3)

$\begin{array}{lcll}\begin{array}{l}\text { Murat } \\ \text { Murat }\end{array} & \text { kitap/ } & \text { kitab-1 } & \text { ok-uyor. } \\ \text { 'Murat is reading a/the book.' } & \text { book-ACC } & \text { read-PROG(3) } \\ \text { *Kitap } & \text { Murat } & \text { ok-uyor. } & \\ \text { Kitab-1 } & \text { Murat } & \text { ok-uyor. } & \\ \text { book-ACC } & \text { Murat } & \text { read-PROG(3) } & \\ \text { 'Murat is reading the book.' } & & \end{array}$

(Erguvanll, 1984:

21-22)

In the example in (3), the direct object kitap 'book' can appear either marked with the accusative case marker or unmarked-both options are acceptable and grammatical. In (4), an attempt is made to move the unmarked direct object out of the IPV position, which results in ungrammaticality, but, as (5) shows, this is acceptable for the case-marked direct object. Note that the accusatively marked direct object in (3) and (5) receives a definite interpretation, while the unmarked direct object in (3) finds its approximate English equivalent in the indefinite article $a$. However, the example in (6) shows that an accusatively marked direct object can receive the indefinite interpretation when it is preceded by the indefinite article bir.

\begin{tabular}{lllll}
\hline (6) & Ben & bir & kitab-1 & oku-du-m. \\
1SG & a & book-ACC & read-PST-1SG \\
& 'I read a certain book.' & & \\
\hline
\end{tabular}

Examples such as that in (6) led Lewis (1967), Erguvanlı (1984), Kornfilt (1997), Enç (1991), Aydemir (2004) and von Heusinger and Kornfilt (2005), amongst many others, to conclude that accusative case must be associated with specificity rather than definiteness.

DOM in Kazakh is of the same type as in Turkish-asymmetric, in the sense that a direct object is either unmarked or marked with an accusative case marker, as in (7) and (8). 


\begin{tabular}{llll}
\hline (7) & $\begin{array}{l}\text { kolat } \\
\text { Bolat }\end{array}$ & $\begin{array}{l}\text { kitap } \\
\text { book }\end{array}$ & $\begin{array}{l}\text { satïp al-dï. } \\
\text { buy-PST(3) }\end{array}$ \\
'Bolat bought a book.' & & \\
Bolat & kitap-tï & satïp al-dï. \\
Bolat & book-ACC & buy-PST(3) \\
'Bolat bought the book.' & & \\
\hline
\end{tabular}

Similarly to the Turkish examples, it might initially seem that the accusative case marking has to do with definiteness; however, as in Turkish, an indefinite direct object can also be case-marked, as in (9) below.

\begin{tabular}{|c|c|c|c|c|}
\hline \multirow[t]{2}{*}{ (9) } & Men & bir & kitap-tï & satïp al-dï-m. \\
\hline & $1 \mathrm{SG}$ & $\mathrm{a}$ & book-ACC & buy-PST-1SG \\
\hline
\end{tabular}

The indefinite specific interpretation of the direct object in (9) points to specificity also being the crucial ingredient in Kazakh DOM.

As in Turkish, an accusatively marked direct object in Kazakh is not restricted to the immediately preverbal position, and can be placed anywhere in the preverbal area, as in (10) where it is sentence-initial, and can also appear post-verbally, as in (11).

\begin{tabular}{|c|c|c|c|}
\hline \multirow[t]{2}{*}{ (10) } & $\begin{array}{l}\text { Kitap-tï } \\
\text { book-ACC }\end{array}$ & $\begin{array}{l}\text { Bolat } \\
\text { Bolat }\end{array}$ & $\begin{array}{l}\text { satïp al-dii. } \\
\text { buy-PST(3) }\end{array}$ \\
\hline & 'Bolat boug & 'As for the bo & at it.') \\
\hline \multirow[t]{3}{*}{ (11) } & Bolat & satïp al-dï & kitap-tï. \\
\hline & Bolat & buy-PST(3) & book-ACC \\
\hline & 'Bolat boug & 'Bolat bough & \\
\hline
\end{tabular}

The examples in (12)-(15) show the ungrammaticality of an unmarked direct object appearing anywhere other than in the IPV position.

\begin{tabular}{lllll}
\hline (12) & $*$ Kitap & Bolat & satïp & aldi. \\
$(13)$ & $*$ Bolat & satïp & aldi & kitap. \\
$(14)$ & $*$ Bolat & kitap & keše & satïp aldi. $^{2}$ \\
& Bolat & book & yesterday & buy-PST(3) \\
& Intended: 'Bolat bought a book yesterday.' \\
(15) & $*$ Bolat kitap & düken-nen & satïp aldï \\
\hline
\end{tabular}

\footnotetext{
${ }^{2}$ A reviewer notes that the word keše is "not of type $e$ " which should pose an issue for the proposed DS analysis of this and similar sentences. I follow Marten (2002) who posits that adjuncts like keše "yesterday' are in fact of type $e$. As Seraku and Gibson (2016) observe, Marten's account provides for a simplified approach to adjuncts, the alternative being the introduction of a type $e$ situation term (Gregoromichelaki 2006); either way, keše is, indeed, parsed onto a node of type $e$ which makes its appearance between an unmarked DO and the predicate unacceptable due to the reasons outlined in Sect. 4.3.
} 
Bolat book shop-ABL buy-PST(3)

Intended: 'Bolat bought a book in the shop.'

\subsection{Previous Descriptions of Kazakh DOM}

Traditionally, Kazakh grammars of the early and mid-twentieth century written in the USSR (in Russian) refer to marked and unmarked direct objects as oformlennye (literally: 'framed' or 'decorated'), and neoformlennye ('unframed' or 'undecorated') respectively. Balakaev's (1959) tome Sovremennyj Kazakhskij Jazyk—Sintaksis 'Modern Kazakh Language-Syntax' provides the most detailed description of DOM in the literature of that era, and presents a functional approach to the phenomenon.

Balakaev (1959) states that all explanations of differential object marking in Turkic languages proposed by both Soviet and pre-Soviet linguists point to DOM being dependent on the "grammatical definiteness or indefiniteness of the direct object's referent. The speaker's awareness/knowledge or unawareness/lack of knowledge of the referent are the determinant features of definiteness and indefiniteness respectively" (1959: 162). ${ }^{3}$ Balakaev does not support this point of view and proposes to separate nouns into 'potential objects' and 'potential subjects', where the former respond to the question What?, and the latter to Who?. According to him, then, 'potential objects' can be either marked or unmarked when functioning as direct objects, while the nominals that are not 'potential objects' must be marked. Contrary to Balakaev, Muhamedowa (2016) states that the accusative case suffix "indicates whether the direct object is definite or non-definite. The definite direct object must bear the accusative suffix" (2016: 228).

Keeping the notions of definiteness and specificity aside, what Balakaev's and Muhamedowa's observations and examples primarily demonstrate is that the accusative case-marking is obligatory when direct-objecthood needs to be overtly confirmed. However, contrary to Balakaev's approach, I do not claim that a direct object needs to be accusatively marked in order to be distinguished from the subject, as by and large, this is not the case in all instances of obligatory case marking of a direct object.

Having described the phenomenon at hand, I now move to its previous analyses. Due to the lack of analytical work on Kazakh DOM, in the following sub-section I briefly consider the previous analyses of Turkish DOM which operates in much the same way as its Kazakh counterpart.

3 This and all other translations from Russian sources are mine. 


\section{Previous Analyses of Differential Object Marking in Turkish}

As far as DOM in Turkish is concerned, the discussions in the literature focus on two main questions: (1) the syntactic status of marked versus unmarked direct objects; and (2) the difference in the semantics and pragmatics of marked and unmarked direct objects. In the following sections I briefly outline the main points of the analyses aimed at answering these two questions.

\subsection{Syntactic Status of Marked Versus Unmarked Direct Objects}

The main discussion regarding the difference in the syntactic status of marked and unmarked direct objects in Turkish revolves around the concept of object incorporation; more precisely, the syntactic and the partial semantic incorporation types. This section presents Orgun and Inkelas's (2004) arguments against the incorporation analysis for Turkish unmarked direct objects; these counter-arguments are also extended to Kazakh.

Incorporation is the compounding of a word (usually a verb or a preposition) with another element (usually a noun, pronoun or an adverb) in such a way that the resulting compound "serves the combined syntactic function of both elements" (Gerdts, 1998: 84). In object incorporation specifically, the verb forms a compound with the direct object, while preserving its syntactic function; the direct object appears inside the verb phrase, as opposed to forming an independent constituent.

It is posited that in Turkish, unmarked direct objects are incorporated, and positioned within the head of the VP; while marked, non-incorporated direct objects are V-external and take up the spec position within the VP. The incorporation claims are mainly based on the lack of accusative case marking, and on the observation that these unmarked objects are confined to the IPV position, as the examples in the preceding section demonstrated. Erguvanlı (1984), Mithun (1984), Kuribayashi (1989), Gerdts (1998), Kornfilt (2003) and Aydemir (2004), amongst others, maintain that unmarked direct objects in Turkish are incorporated, while Kornfilt (1984) and Orgun and Inkelas (2004), amongst others, are against this view.

The difference between the non-incorporated and incorporated direct objects is traditionally represented as shown in (16) and (17) respectively, simplified after Baker (1988: 80). 

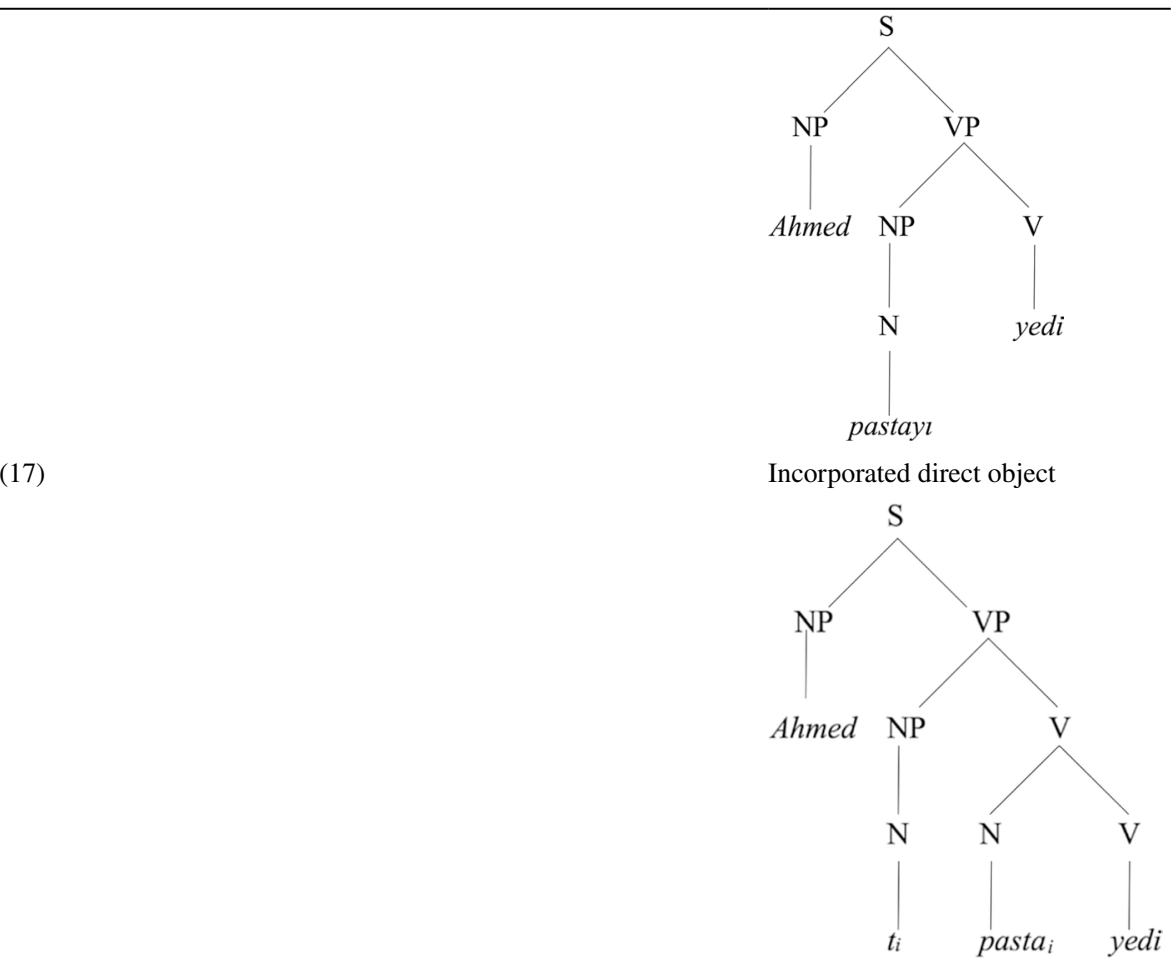

As (16) and (17) show, the assumption is that unmarked, incorporated direct objects are structurally much closer to the verb than marked, non-incorporated direct objects, which form an independent syntactic phrase. In (17), where the direct object is assumed to be incorporated, the moved noun root leaves a trace $\left(t_{i}\right)$ which heads a direct object phrase that receives a theta role from the verb thus satisfying the verb's subcategorisation requirements. Kornfilt (2003) develops this analysis by assuming that DPs are in fact embedded within Case Phrases (KPs), where the K-head is phonologically filled with an overt case-marker, the N-head is unable to move into the $\mathrm{V}$, whereas if the $\mathrm{K}$-head position is empty, the $\mathrm{N}$ can move into that position and then further into the V. The DS analysis presented in Sect. 4 does away with the need to introduce a new arbitrary phrasal category, unobservable movement, or assumed phonological processes.

As mentioned earlier, there is no consensus on the incorporation analysis, and Orgun and Inkelas (2004) present phonological, lexical, and syntactic evidence against this view. Following Gerdts (1998), the authors state that although theoretical approaches to incorporation might differ in many ways, one central assumption is the same-the structure resulting from noun incorporation is a (compound) word. ${ }^{4}$

\footnotetext{
4 The term 'word' is used here as a descriptive term denoting a meaningful standalone unit of a language.
} 
From a phonological point of view, the first member of a compound is typically stressed, like in the examples in (18), where stress is indicated by acute accent.

a)

b)

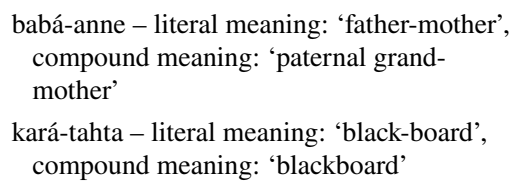

(Orgun \&

Inkelas,

2004: 266)

At first blush, the unmarked direct object-verb sequences seem to have the same stress pattern as the lexical compounds above, which differs from the stress pattern with case-marked direct objects, as in (19) and (20), where the stress is indicated by an accent mark.

\begin{tabular}{|c|c|c|}
\hline Zeynep & kitab-1 & oku-dú. \\
\hline Zeynep & book-ACC & read-PST(3) \\
\hline \multicolumn{3}{|c|}{ 'Zeynep read the book.' } \\
\hline Zeynep & kitáp & oku-du. \\
\hline Zeynep & book & read-PST(3) \\
\hline
\end{tabular}

(Orgun \&

Inkelas,

2004: 266)

Orgun and Inkelas demonstrate, however, that the stress patterns shown in (19) and (20) can change under the influence of information-structural effects, as shown in (21) and (22).

\begin{tabular}{llll}
\hline (21) & $\begin{array}{l}\text { Zeynep } \\
\text { 'Zeynep }\end{array}$ & \multicolumn{1}{c}{$\begin{array}{l}\text { kitabí } \\
\text { read the BOOK (not something else).' }\end{array}$} & \\
'Zeynep read the book.' & \\
(22) & keynep & kitap & oku-dú. \\
'Zeynep & DID & reading.' & \\
& & & (Orgun \& \\
& & & 2nkelas, \\
& & & 2004: 267) \\
\hline
\end{tabular}

The change of stress placement in (21) and (22), as compared to their pragmatically neutral counterparts in (19) and (20) respectively, indicates contrastive focus on the direct object in (21), and verum focus in (22), as reflected in the English interpretations. Orgun and Inkelas observe that such pragmatically determined change in the stress pattern is not characteristic of lexically-determined 
word stress, which points to the phrasal rather than incorporated and compounded nature of unmarked direct object-verb combinations.

Lexical integrity is another criterion of word-hood considered by Orgun and Inkelas in relation to the direct object incorporation analysis. By lexical integrity they mean the impossibility of another syntactic element intruding within the word, or of syntactic permutation of word-internal elements (for example, pre- or postposing one morpheme). The authors show that a wide range of syntactic elements can intervene between an unmarked direct object and a verb. Amongst such elements are: the question particle $m I$, the particle $D A$ 'too', particles like bile 'even', certain clitics, and reduplicated stems, as shown in $(23) .^{5}$

$\begin{array}{lllll}\text { Gül } & \text { bugün } & \text { kitap } & \mathrm{m} 1 & \text { oku-du? } \\ \text { Gül } & \text { today } & \text { book } & \mathrm{Q} & \text { read-PST(3) }\end{array}$

'Is it a book/books that Gül read today?'

(Orgun \&

Inkelas,

2004: 269)

The final piece of evidence against the incorporation analysis relates to the possible syntactic complexity of unmarked direct objects. Orgun and Inkelas observe that according to the incorporation hypothesis, the direct object should be a stem or a word, but not a syntactic phrase. However, this is not the case since non-casemarked direct objects can be syntactically complex, contain determiners, quantifiers, adjectives, relative clauses, or a combination of these elements. The example below, in which the unmarked direct object is modified by the quantifier $\ddot{u} c ̧$ 'three', illustrates this point.

\begin{tabular}{lllll}
\hline Ali & üç & şiir & yaz-di. \\
Ali & three & poem & write-PST(3) & \\
'Ali wrote three poems.' & & & \\
& & & (Orgun \& \\
& & & Inkelas, \\
& & & 2004: 271) \\
\hline
\end{tabular}

It is noteworthy that Orgun and Inkelas also argue against the semantic incorporation analysis for Turkish unmarked direct object-verb sequences, which, according to van Geenhoven (1998), can happen independently from syntactic incorporation. In semantic incorporation, the verb and the incorporated argument create a unit that identifies an activity. The examples such as that in (25) below fit this description of semantic incorporation.

\footnotetext{
5 This is also possible in Kazakh, although, not every speaker accepts such interventions. Due to the low frequency of these constructions and space restrictions, I do not consider them in the analysis proposed below. It must be noted, however, that they do not pose an issue for the proposed analysis, since question and other particles do not carry a semantic expression (formula) which, in DS terms, means that their parsing does not result in the construction of a type $e$ node between an unmarked DO and the predicate.
} 


$\begin{array}{llll}\text { (25) Ahmet } & \text { hergün } & \text { pipo } & \text { iç-iyor. } \\ \text { Ahmet } & \text { every.day } & \text { pipe } & \text { smoke-PROG }\end{array}$

'Ahmet smokes a pipe (engages in pipe-smoking) every day.'

(Mithun, 1984)

Orgun and Inkelas underline that although examples such as (25) might manifest semantic incorporation, not all sequences of an unmarked direct object and verb display semantic incorporation. The authors illustrate this point with the examples in (26) below.

\begin{tabular}{|c|c|c|c|c|c|}
\hline (26) & a) & $\begin{array}{l}\text { bir } \\
\text { one } \\
\text { 'I am looking for a doctor.' } \\
\text { üç } \\
\text { three } \\
\text { 'I know three doctors.' } \\
\text { birçok doktor } \\
\text { many } \\
\text { 'I know many doctors.' }\end{array}$ & $\begin{array}{l}\text { doktor } \\
\text { doctor } \\
\text { tan-1yor-um } \\
\text { doctor }\end{array}$ & $\begin{array}{l}\text { tan-1yor-um } \\
\text { know-PROG-1SG }\end{array}$ & $\begin{array}{l}\text { (Orgun \& } \\
\text { Inkelas, } \\
\text { 2004: 272) }\end{array}$ \\
\hline
\end{tabular}

The objects in these examples are referential since the sentences do not describe situations where the subject engages in the activities of 'doctor-knowing', but rather introduces previously unspecified doctors as discourse participants. This also conforms with the canonical information-structural pattern of Turkish (and Kazakh), where the immediately preverbal position is strongly associated with focus, which essentially is the introduction of non-presupposed information. Additionally, since semantic incorporation analysis means activity naming, pluralising an unmarked direct object-which is possible and grammatical-would imply a contrast in the meaning of activity types depending on the quantity of the direct object's referent (Orgun \& Inkelas, 2004).

To sum up, as far as the syntactic status of unmarked direct objects is concerned, two main positions have been presented: the syntactic incorporation analysis, and the partial semantic incorporation analysis. It has been demonstrated that the syntactic incorporation analysis of the unmarked direct object-verb sequences does not withstand the scrutiny proposed by Orgun and Inkelas (2004), meaning that the analyses of Turkish DOM based upon the notion of incorporation do not sufficiently explicate this phenomenon.

\subsection{Semantics and Pragmatics of Marked versus Unmarked Direct Objects}

The notions of definiteness and specificity are central to the discussion of the semantics and pragmatics of marked and unmarked direct objects. Namely, it is posited 
that unmarked direct objects are indefinite and/or non-specific, while their marked counterparts are definite and/or specific.

While it is sometimes proposed that case-marked direct objects in Turkish are definite (Orgun \& Inkelas, 2004, amongst others), von Heusinger and Kornfilt (2005: 41) convincingly demonstrate that specificity is "the most important semantic property that determines overt objective, i.e. accusative case marking in Turkish". The authors employ von Heusinger's (2002) proposal to view specificity as a referential property of noun phrases, which cuts across the definite-indefinite distinction, and results in a fine-grained distinction which does not treat specific expressions as a subclass of indefinite noun phrases.

The relation between accusative case marking and specificity was briefly illustrated in the previous section, and the examples in (27)-(30) below further support this point.

$\begin{array}{lll}\text { Murat } & \text { kitap } & \text { ok-uyor } \\ \text { Murat } & \text { book } & \text { read-PROG }\end{array}$

'Murat is book-reading / is reading a book.'

\begin{tabular}{|c|c|c|c|}
\hline Murat & bir & kitap & ok-uyor. \\
\hline Murat & $\mathrm{a}$ & book & read-PROG \\
\hline \multicolumn{4}{|c|}{ 'Murat is reading a book.' } \\
\hline Murat & kitab-i & ok-uyor. & \\
\hline Murat & book-ACC & read-PROG & \\
\hline \multicolumn{4}{|c|}{ 'Murat is reading the book.' } \\
\hline Murat & bir & kitab-i & ok-uyor. \\
\hline Murat & $\mathrm{a}$ & book-ACC & read-PROG \\
\hline
\end{tabular}

(von Heusinger \& Kornfilt, 2005:

41)

The English approximations of sentences in (27)-(30) show that the unmarked direct object in (27) can receive the incorporated interpretation, as well as the indefinite and non-specific interpretations; the addition of the indefinite article bir in (28) removes the possibility of the incorporated interpretation, and the direct object in this example can only be understood as indefinite and non-specific. The case-marked direct object in (29) has the definite and specific interpretation, and the case-marked direct object preceded by the indefinite article bir in (30) is interpreted as indefinite, but specific.

While von Heusinger's (2002) and von Heusinger and Kornfilt's (2005) conclusions regarding possible interpretations of accusatively marked direct objects in the IPV position are convincing and comprehensive, they do not provide an explanation of how the pragmatic interpretation of specificity is achieved. An assumption seems to be made that an accusative case marker contributes the pragmatics of specificity, which, in turn, implies that accusative is not a structural/morphological case.

In the same vein, Orgun and Inkelas explicitly state that since accusative case marking is used only for definite objects, the accusative case "is not in fact purely 
structural" (2004: 276). This, of course, is a problematic statement, since the only supporting evidence for it lies in pragmatic interpretations of marked direct objects. Additionally, these approaches to accusative case marking of immediately preverbal direct objects do not explain the ability of the case-marked direct objects to appear anywhere in a sentence, and the inability of unmarked direct objects to do so.

As previously mentioned, all the analyses of Turkish DOM presented here can be applied to Kazakh DOM; the same questions and reservations would subsequently hold too. In what follows, I propose an alternative approach to DOM in general, and to DOM in Kazakh and Turkish in particular. The proposed DS analysis does away with the need to posit certain syntactic characteristics specific to one or another sentential position, or to claim that one of the case markers carries some additional meanings (e.g. specificity or definiteness). All pragmatic effects and syntactic restrictions are explicated via a difference in the parsing of marked and unmarked direct objects.

\section{Kazakh DOM: The Dynamic Syntax Approach}

As mentioned in the preceding section, no formal analyses have been published for Kazakh DOM, and previous analyses of Turkish DOM focus on the differences in the syntactic, semantic and pragmatic features of marked and unmarked direct objects. These analyses have yet to reach a consensus, and to produce an insight that goes beyond the descriptive terms of topicality, incorporation, animacy, definiteness, or specificity, none of which cover all instances of DOM in either Turkish or Kazakh.

Applying the $\mathrm{DS}^{6}$ approach to the phenomenon of DOM in Kazakh means switching from the traditional 'static' view of syntax to examining DOM within the dynamic process of incremental parsing, as it unfolds step-by-step. This delivers a new understanding of the phenomenon and its mechanisms. This, in turn, allows us to move away from simply recounting the syntactico-semantic characteristics of differentially marked direct objects in a static sentence, which, fundamentally, leads to a cyclical explanation of the phenomenon along the lines of: the direct object is marked because it is specific (or definite/animate/human/topical), and it is understood to be specific (or definite/animate/human/topical) because it is marked. ${ }^{7}$

\footnotetext{
6 The reader is referred to the first paper of this special issue for an introduction to Dynamic Syntax.

7 A reviewer notes, that they do not see a problem with stating that "we have a lexical marker for specificity on direct objects, which is what we call the accusative suffix". It appears rather problematic to me that one of the six case markers available in the Kazakh language would carry the notion of specificity. In fact, we know this not to be true, since the Genitive case-marking can also produce the pragmatic effect of specificity when it is used to mark the subject of a subordinate clause; the same is observed in Turkish (Kornfilt 2009). Due to space limitations, I am unable to provide a detailed analysis of Kazakh differentially marked subjects (in subordinate clauses), however, I believe that the general idea behind the analysis proposed here for DOM would be transferrable to that phenomenon too.
} 


\subsection{The Proposed Analysis}

Before I turn to the analysis of the phenomenon at hand, the following two points need to be taken into consideration. Firstly, let us consider the DS approach to the role of case-marking suffixes, as noted in Cann et al. (2005: 240):

What the case suffixes ensure is the progressive build-up of interpretation for the constituent that it marks. Each suffix indicates that all that is needed to interpret the constituent whose end it marks is already given. The action defined by a suffix, that is, takes some decorated node, with type-requirements satisfied, and adds some additional specification. It is this form of the input condition that is critical, as it is the simple mechanism of fixing a type specification as the input condition which ensures that all non-terminal nodes dominated by the node in question must have already been decorated with a type and formula specification. Hence, the effect of case is to determine the completed assignment of interpretation to the noun phrase sequence, what we might call its "sealing-off" function.

The analysis proposed below is ultimately developed around this "sealing-off" function of case-markers and other signals that different languages might employ for this purpose.

Secondly, I return to the claim made in Sect. 1 that there are no unmarked noun phrases in Kazakh, despite the widespread usage of the term 'unmarked' to describe Kazakh subjects and direct objects without overt case markers; every noun phrase in this language must be marked one way or another. The available marking options are: a case-marker, an IP boundary, both a case-marker and an IP boundary, or the lack of both a case marker and an IP boundary; the latter indicates that the parser cannot fix this noun phrase within the semantic tree until after the predicate (which should follow immediately) is parsed. The question of the use of all of these markers and their distribution in Kazakh (and many related languages) is the matter for much further research and is beyond the scope of this paper.

Let us now move to examining the parsing process for a sentence with an accusatively marked direct object, like that in (31) below.

\begin{tabular}{lllll}
\hline (31) & Bolat & kitap-tï & Dana-ğa & berdi. \\
Bolat & book-ACC & Dana-DAT & gave \\
& 'Bolat gave Dana the book.' & & \\
\hline
\end{tabular}

In this sentence, the subject is not case marked, and the direct and indirect objects are marked with the accusative and dative case markers respectively. Traditional grammars state that unmarked subjects are in nominative case; however, since this noun form does not differ from that of unmarked direct objects, I see no grounds for identifying it as a case-marked form, and simply refer to these nouns as bare.

The question then arises as to what differentiates subjects which are always unmarked (in independent matrix clauses: see Footnote 8) from unmarked direct 
objects. On the basis of phonological analysis of a number of Kazakh sentences, I posit that the answer to this question lies in the prosody, and that subjects are in fact prosodically identified by an IP boundary (represented by \%), which functions here like a case marker and identifies subjects as such. For considerations of space, I do not focus on this further, and the reader is referred to Christopher (2018) for a more detailed account; the partial lexical entry for an IP boundary presented in (32) below suffices for the purposes of this paper.

\begin{tabular}{lll}
\multicolumn{2}{l}{ Lexical entry for an IP boundary \% (simplified and partial) } \\
IF & Fo $(\alpha), \operatorname{Ty}(\mathrm{e})$ & \\
THEN & IF & $\left\langle\uparrow \uparrow^{*}\right\rangle(\operatorname{Tn}(\mathrm{a})$, ? Ty $(\mathrm{t}))$ \\
& THEN & $\operatorname{put}(?\langle\uparrow 0\rangle \operatorname{Ty}(\mathrm{t}))$ \\
& ELSE & Abort \\
ELSE & Abort &
\end{tabular}

According to the lexical entry above, the sentence initial subject Bolat\% is fixed as the subject of the sentence, as demonstrated in (33) below. The nominal is first parsed onto a locally unfixed node via the application of the LOCAL *aDJunction rule; once the IP boundary is encountered, this node is fixed as the subject node via a routinised update.

Parsing Bolat\%...

(a) Local *Adjunction

(b) Parsing Bolat

(c)Parsing Bolat \%
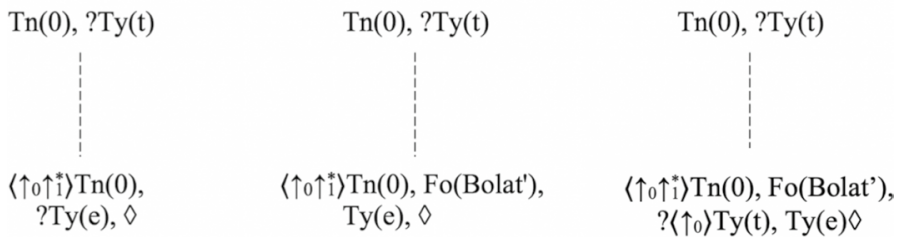

(d) Routinised Update

$\operatorname{Tn}(0), ? \operatorname{Ty}(\mathrm{t}), \diamond$

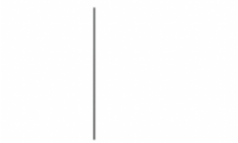

$?\left\langle\uparrow_{0}\right\rangle \operatorname{Ty}(\mathrm{t})$,
$\left\langle\uparrow_{0}\right\rangle \operatorname{Tn}(0), \mathrm{Fo}\left(\right.$ Bolat' $\left.^{\prime}\right), \operatorname{Ty}(\mathrm{e})$

Next in the string is the accusatively marked direct object kitapti. Following Kiaer (2007) and Christopher (2018), I propose the following lexical entry for the accusative case marker: 


$\begin{array}{lll}\text { Lexical entry for }-D I /-n & \text { (accusative) } & \\ \text { IF } & \operatorname{Fo}(\alpha), \operatorname{Ty}(\mathrm{e}) & \\ \text { THEN } & \text { IF } & \left\langle\uparrow_{0} \uparrow^{*}\right\rangle(\operatorname{Tn}(\mathrm{a}), ? \mathrm{Ty}(\mathrm{t})) \\ & \text { THEN } & \operatorname{put}\left(?\left\langle\uparrow_{0}\right\rangle \mathrm{Ty}(\mathrm{e} \rightarrow \mathrm{t})\right) \\ & \text { ELSE } & \text { Abort } \\ \text { ELSE } & \text { Abort } & \end{array}$

This lexical entry shows that the accusative case marker follows a nominal appearing on an unfixed node, and fixes it as the direct object. According to this lexical entry, the accusative case marker is the marker of direct-objecthood only and carries no additional pragmatic features of definiteness or specificity. The parsing of the direct object is illustrated in (35): when kitap-ti is parsed, kitap

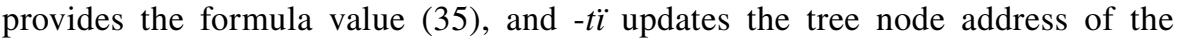
newly introduced tree node (35) via routinised update (35). In other words, during the routinised update, the tree node address changes from " $\left\langle\uparrow_{0}\right\rangle\left\langle\uparrow_{1}{ }^{*}\right\rangle \operatorname{Tn}(0)$ " to " $\left\langle\uparrow_{0}\right\rangle\left\langle\uparrow_{1}\right\rangle \operatorname{Tn}(0)$ " which identifies the nominal parsed onto this node as the direct object. The routinised update also brings the pointer back up to the root node, in readiness for parsing the next item in the string.

Parsing Bolat \% kitaptï...

(a) After Bolat $\%$ has been parsed

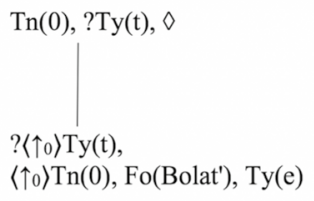

(c) Parsing Bolat \% kitap-ti...

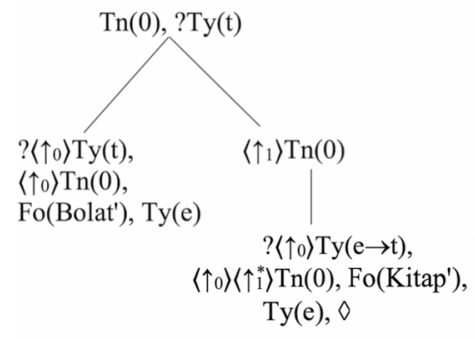

(b) Parsing Bolat $\%$ kitap...

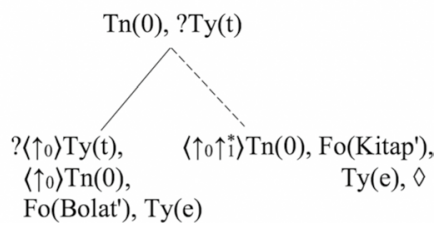

(d) Routinised Update

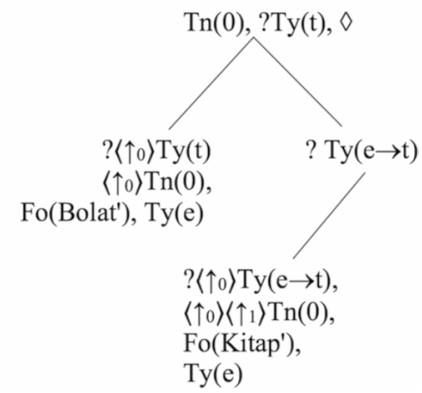


The indirect object Dana $\breve{g} a$ marked by the dative case is parsed next. The lexical entry for the dative case marker is provided below.

\begin{tabular}{|c|c|c|c|}
\hline \multirow{2}{*}{$\begin{array}{l}\text { (36) } \\
\text { Christopher (2018) }\end{array}$} & \multicolumn{3}{|c|}{ Lexical entry for - $\breve{G} A /-n A /-A{\text { (dative })^{8}}^{8}$} \\
\hline & IF & $\operatorname{Fo}(\alpha)$ & \\
\hline & \multirow[t]{3}{*}{ THEN } & IF & $\left\langle\uparrow_{0} \uparrow_{i}^{*}\right\rangle(\operatorname{Tn}(\mathrm{a}), ? \mathrm{Ty}(\mathrm{t}))$ \\
\hline & & THEN & $\operatorname{put}(?\langle\uparrow 0\rangle \operatorname{Ty}((\mathrm{e} \rightarrow(\mathrm{e} \rightarrow \mathrm{t})))$ \\
\hline & & ELSE & Abort \\
\hline & ELSE & Abort & \\
\hline
\end{tabular}

The semantic tree resulting from the parsing of the indirect object is shown in (37).

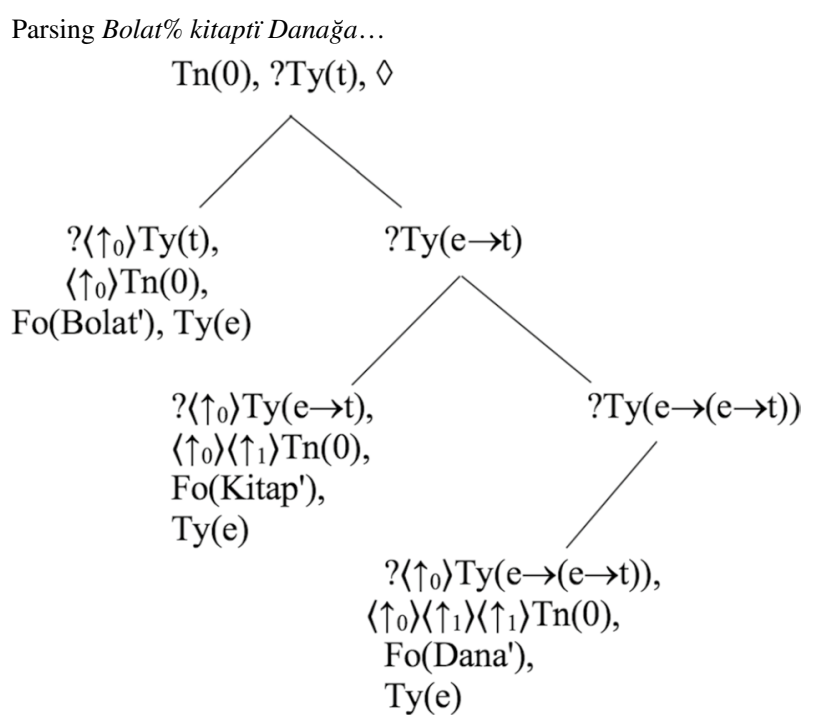

Lastly, the verb is parsed; the simplified lexical entry for berdi is presented in (38) below. This lexical entry shows that Kazakh verbs project full argument-predicate structures with metavariables decorating the argument nodes. The fact that in some cases the same argument node is constructed twice (as indeed is the case for the string at hand) does not pose an issue: if two nodes with the same location are constructed in the same tree, they are simply identified as one and the same node.

\footnotetext{
${ }^{8}$ The dative suffix in Kazakh can be of the form $-\breve{G} A$, $-n A$, or $-A$ depending on the quality of the immediately preceding element. 


\begin{tabular}{ll}
\hline Lexical entry for berdi 'gave' & $($ simplified $)$ \\
IF & ?Ty(t) \\
THEN & $\operatorname{put}(\operatorname{Tns}(\operatorname{PAST})) ;{ }^{9}$ \\
& $\operatorname{make}\left(\left\langle\downarrow_{0}\right\rangle\right) ; \operatorname{go}\left(\left\langle\downarrow_{0}\right\rangle\right) ; \operatorname{put}(\operatorname{Fo}(\mathbf{U}), \operatorname{Ty}(\mathrm{e}), ? \exists \mathrm{x} . \operatorname{Fo}(\mathrm{x})) ; \operatorname{go}\left(\left\langle\uparrow_{0}\right\rangle\right) ;$ \\
& $\operatorname{make}\left(\left\langle\downarrow_{1}\right\rangle\right) ; \operatorname{go}\left(\left\langle\downarrow_{1}\right\rangle\right) ; \operatorname{put}(? \operatorname{Ty}(\mathrm{e} \rightarrow \mathrm{t})) ;$ \\
& $\operatorname{make}\left(\left\langle\downarrow_{0}\right\rangle\right) ; \operatorname{go}\left(\left\langle\downarrow_{0}\right\rangle\right) ; \operatorname{put}(\operatorname{Fo}(\mathbf{V}), \operatorname{Ty}(\mathrm{e}), ? \exists \mathrm{x} . \operatorname{Fo}(\mathrm{x})) ; \operatorname{go}\left(\left\langle\uparrow_{0}\right\rangle\right) ;$ \\
& $\operatorname{make}\left(\left\langle\downarrow_{1}\right\rangle\right) ; \operatorname{go}\left(\left\langle\downarrow_{1}\right\rangle\right) ; \operatorname{put}(? \operatorname{Ty}(\mathrm{e} \rightarrow(\mathrm{e} \rightarrow \mathrm{t})) ;$ \\
& $\operatorname{make}\left(\left\langle\downarrow_{0}\right\rangle\right) ; \operatorname{go}\left(\left\langle\downarrow_{0}\right\rangle\right) ; \operatorname{put}(\operatorname{Fo}(\mathbf{W}), \operatorname{Ty}(\mathrm{e}), ? \exists \mathrm{x} . \operatorname{Fo}(\mathrm{x})) ; \operatorname{go}\left(\left\langle\uparrow_{0}\right\rangle\right) ;$ \\
& $\operatorname{make}\left(\left\langle\downarrow_{1}\right\rangle\right) ; \operatorname{go}\left(\left\langle\downarrow_{1}\right\rangle\right) ; \operatorname{put}(\operatorname{Fo}(\operatorname{Ber}), \operatorname{Ty}(\mathrm{e} \rightarrow(\mathrm{e} \rightarrow(\mathrm{e} \rightarrow \mathrm{t}))),[\downarrow] \perp) ;$ \\
& $\operatorname{Abort}$
\end{tabular}

The final semantic tree for the string Bolat kitaptï Dana $\breve{a} a$ berdi is presented below.

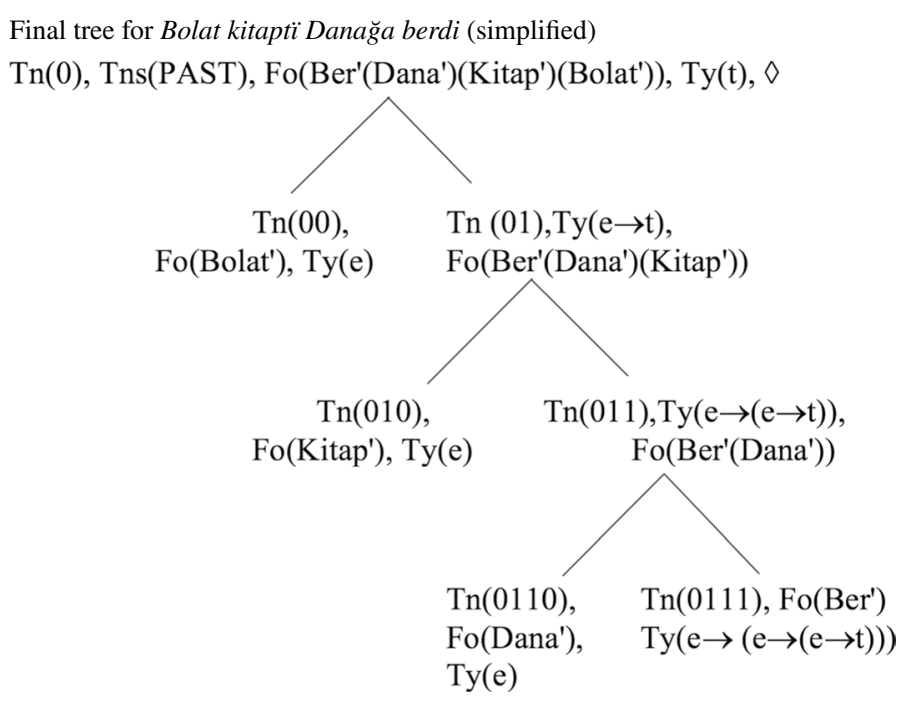

I now move to examining the development of the parsing process for a sentence with a non-case-marked direct object as in (40). Note that the direct object is now in the IPV position.

$\begin{array}{llll}\text { Bolat } & \text { Dana-ğa } & \text { kitap } & \text { berdi. } \\ \text { Bolat } & \text { Dana-DAT } & \text { book } & \text { gave } \\ \text { 'Bolat gave Dana a book.' } & & \end{array}$

${ }^{9}$ To be precise, this decoration along with the bottom restrictor is projected specifically by the tense marking suffix $-d i$ (ber-di 'give-PST.3'), however, this point is not vital for our discussion. Therefore, a simplified version of the lexical entry which combines the contributions of both the lexical verb root and the suffix is presented. A detailed DS account of Kazakh (and generally speaking Turkic) tense markers is a vast topic for future research. 
The first two nominals are parsed as previously shown, and fixed as the subject and the indirect object of a partial tree, as shown below.

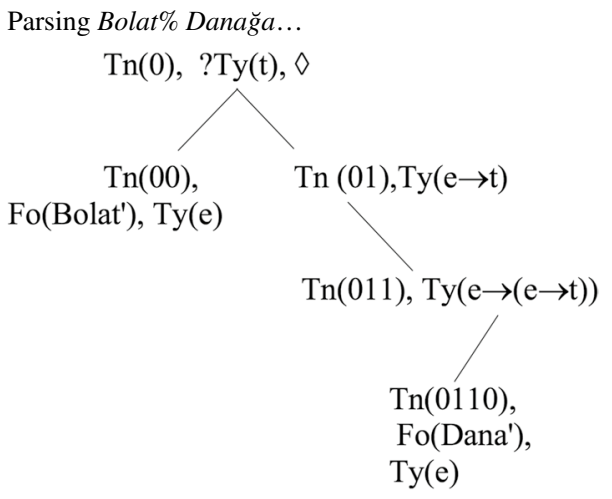

Next, the unmarked noun kitap must be parsed. Recall that an IP boundary indicates that an unmarked sentence-initial nominal is the subject. In the case of an unmarked direct object in the IPV position, the lack of both an IP boundary and a case marker indicates that this constituent forms one IP with the following constituent and is to be parsed in relation to it. In DS terms, this means that a node onto which such an unmarked nominal is parsed remains unfixed, as in (42).

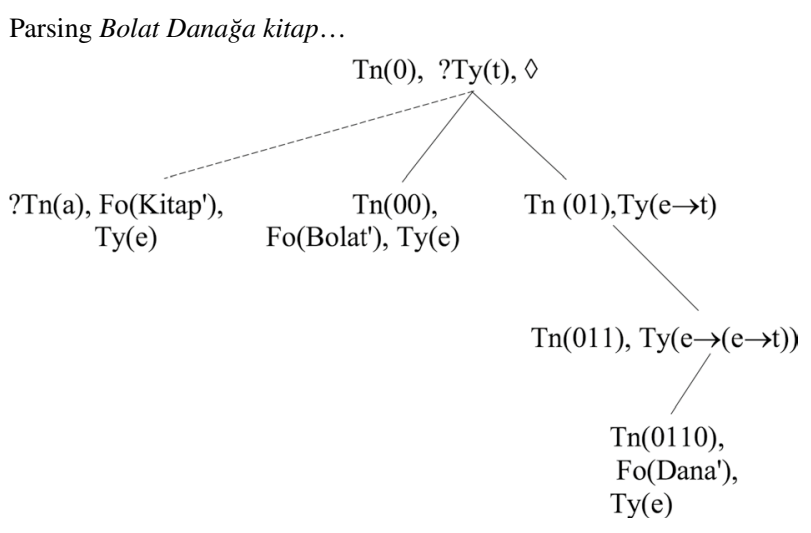

The verb berdi follows the unmarked direct object and projects the full argument structure, as per the lexical entry given in (38). 


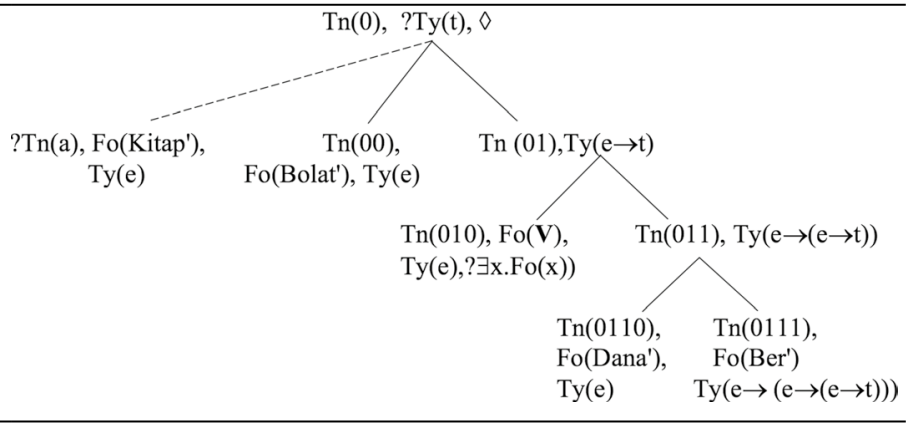

At this stage we have an incomplete tree with an unfixed node, and with a fixed $\operatorname{Tn}(010)$ node with a variable and a requirement for it to be substantiated with a semantic formula. Both these nodes are of type $e$, and have no decorations that might prevent their MERGE, which is precisely what occurs:

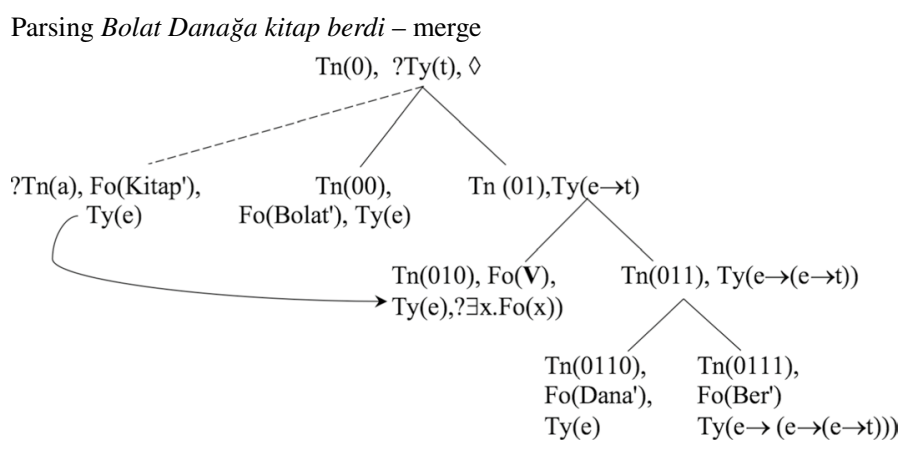

In (45), we see the final tree after the MERGE, and after all the clean-up and completion processes have taken place.

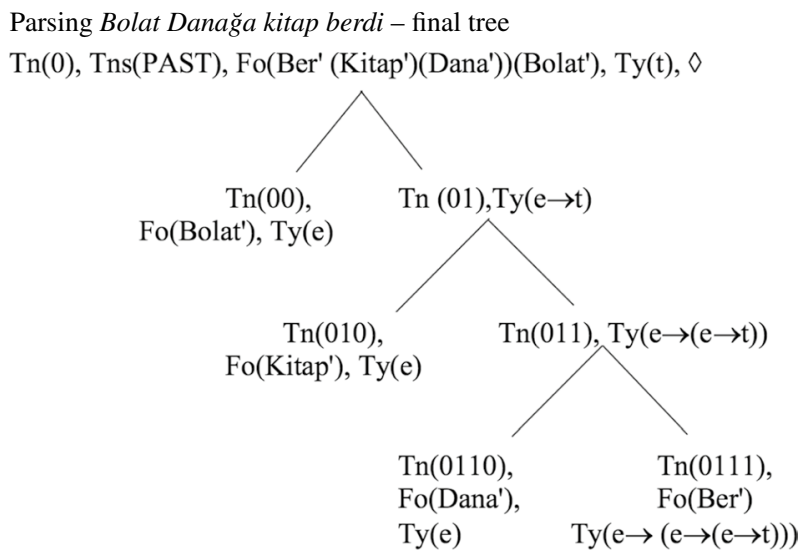


This tree is identical to that in (39) for the sentence Bolat kitapti Danağa berdi, which demonstrates that the DS analysis of DOM does not rely on any differences in theory-specific hierarchical syntactic structuring of a sentence.

\subsection{Discussion}

Having considered the parsing processes for the trees with a case marked and a noncase-marked direct object, we can get closer to explicating the nature of Kazakh DOM. We have seen that, in Kazakh, there are two grammatical categories that can appear without a case marker: subjects and direct objects. It has been shown, however, that in lieu of a case marker, subjects are identified by an IP boundary and cannot be viewed as completely unmarked, since the parser receives a discernible signal which allows these non-case-marked nominals to be parsed as subjects. This means that these non-case-marked nominals appear on a fixed node before the parsing of the next element in the string begins, as is typical for and preferred in Kazakh with its 'fix-as-you-go' parsing strategy.

Non-case-marked direct objects, on the other hand, remain unfixed until the predicate following them is parsed, since neither a case marker nor an IP boundary is present to fix the nodes onto which they are initially parsed. However, this lack of both a case marker and an IP boundary also constitutes a signal to the parser that the nominal at hand forms an IP with the following constituent, and will be fixed after that constituent has been parsed. This distinguishes non-case-marked direct objects from other types of arguments, since they appear to be the only type of argument to be parsed onto and to remain on an unfixed node until the following constituent is parsed.

This underspecified, unfixed position taken by a non-case-marked direct object in a semantic tree is symbolic of non-specific, indefinite, generic and (occasionally) pseudo-incorporated readings with which unmarked direct objects are so strongly associated in Kazakh and Turkish, as described in the previous sections. The DS representation of this, given in (43) above, provides for an intuitive and accurate explication of the interpretations unmarked direct objects receive, and of their relation with the predicate.

This observation, however, should not be taken out of the overall context of the parsing process in Kazakh which, as mentioned earlier, strives for the fastest possible resolution of any uncertainties within a tree-a 'fix-as-you-go' strategy. The divergence from this usual strategy which we see in the parsing of a non-casemarked direct object yields the pragmatic effects of non-specificity and even pseudosemantic-incorporation (where there are no other factors precluding it, as pointed out in Sect. 3.1).

In contrast to non-case-marked direct objects, accusatively marked direct objects obtain a fixed position in the semantic tree before the parsing of the following constituent begins. This signals a difference in the interpretation: a case-marked direct object is fixed in the semantic tree, and, by cognitive extension is associated with 
a specific ("fixed") referent in the real world (and vice versa). ${ }^{10}$ This yields the pragmatic effect of specificity strongly associated with accusatively marked direct objects in Kazakh (cf. Cann and Miljan's (2012) analysis of case marking and casealternation in Estonian). This distinction is particularly strong for the direct objects in the IPV position, since this is the only position in which an unmarked direct object can appear. The big question that remains for future investigation is the diachronic development of DOM in Kazakh: was the accusative case marker obligatory for all the direct objects or for none of them?

\subsection{Extensions and Constraints}

The proposed analysis extends to explicate the special nature of the IPV position (within a linear linguistic string): it is special due to its ability to 'host' a temporarily unfixed node of type $e$, since it guarantees that this node will be fixed at the next step of the parsing process. This removes the need to posit a special syntactic relation of a non-case-marked direct object with the predicate, as per some of the incorporation analyses of Turkish DOM. Both case-marked and unmarked direct objects eventually take up the same $\operatorname{Tn}(010)$ position in DS semantic trees, with the former getting there faster than the latter, and independently from the predicate.

This approach to the difference between case-marked and non-case-marked direct objects also explains the ungrammaticality of unmarked direct objects appearing outside of the IPV position, as shown in (46).

*Bolat kitap Danağa berdi.

Intended: 'Bolat gave a book to Dana.'

Once the subject and the unmarked direct object are parsed, we end up with the following partial tree:

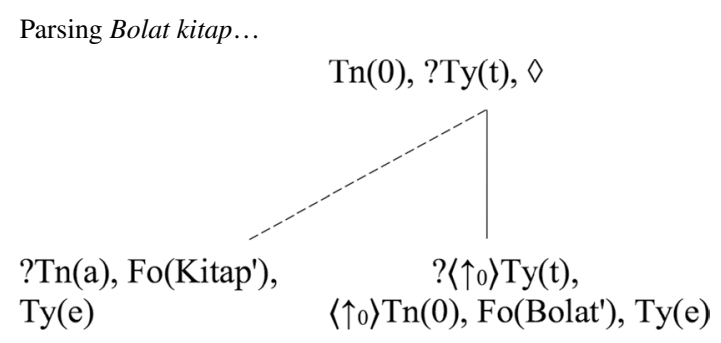

Then, another nominal constituent must be parsed, before we reach the predicate which projects a fixed structure and enables the merge of the unfixed node present

\footnotetext{
10 I believe this claim is very much in line with Cann and Kempson's (2017) views on the notions of word, grammar, and metaphor, and with their general observation that "interaction of language, nonlinguistic stimuli and the local environment of an exchange provides meanings for participants and yields external significance to the actual linguistic expressions used" (2017: 456).
} 
in this tree with a fixed one. Recall that each nominal starts off being parsed onto an unfixed node (via LOCAL *ADJUNCTION) before being fixed into place by either a casemarker or an IP boundary. This is when we encounter an issue since two unfixed nodes of the same type (locally unfixed in our case) but with different formula decorations cannot simultaneously be present in one tree:

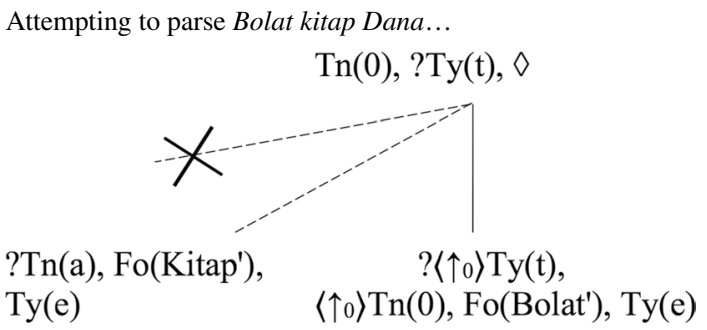

Restricting unmarked direct objects to the IPV position prevents this from occurring.

The proposed analysis, combined with the DS view on the function of suffixes, and some general principles of semantic tree-growth process, captures the ungrammaticality of (13), repeated below for convenience.

*Bolat satïp aldi kitap

The ungrammaticality of sentences where an attempt is made to place a noncase-marked direct object in the post-verbal position is explicated independently from the proposed analysis through the application of several general principles of DS. Firstly, Cann et al. observe that the function of case marking suffixes (see 4.1) "extends directly to tense" (2005: 240). In the same way as Cann et al. propose for Japanese, the processing of a tense suffix in Kazakh signals that all elements required for a successful establishment of a propositional structure are already present. Thus, once the parser processes the past tense marker -DI [as in (49)], the full argument structure is built up, and the variable at the direct object node is updated with an appropriate semantic formula from the context. All the completion and clean-up procedures then take place and the compilation of the final semantic tree is finished; the parser is at the root node of a tree with no outstanding requirements.

As outlined in Cann et al., once some mother node is decorated on the basis of the rules of COMPLETION and ELIMINATION, there can be no return to any of its daughter nodes since "the addition of any further decorations on these nodes would lead to the modification of the decorations on the mother node in the light of any such changes which is incompatible with the monotonicity of the tree-growth process, the centre pin of the concept of tree growth" (2005: 189). This means that the post-verbal noncase-marked direct object which is parsed onto an unfixed node cannot merge with any fixed node within the completed tree, and obtain a fixed node address, thus causing the ungrammaticality.

This, of course, leads to the natural question about the grammaticality of case marked direct objects in the post-verbal position, as in (11), which is an example 
of right dislocation (RD). Further research is required in order to identify whether there are different types of RD in Kazakh and, if so, what the distinct features of these types are (cf. Valiouli, 1994 for Greek). However, it can still be proposed at this point, that a right-dislocated argument is parsed onto a LINKed structure (see Cann et al. 2005 for English; Chatzikyriakidis, 2017 for Modern Greek). Thanks to the accusative case marker, a case marked direct object can be parsed onto a fixed node within a partial LINKed tree with a requirement to find a copy of itself in the main tree. Contrastively, this would not be possible for a non-case-marked direct object, which would still remain unfixed within the partial LINKed tree structure by the time the string ends, again, resulting in the ungrammaticality. The lexical entry for the accusative case given in (34) might need to be adjusted to account for such right-dislocated direct objects.

Another limitation of this analysis pointed out by a reviewer relates to direct objects that are obligatorily case marked (such as proper names or substantivised infinitives, for example). The instances where an accusative case marker must be present regardless of the sentential position of a direct object, are not dealt with directly within this analysis, however, most importantly, the proposed analysis does not prevent obligatory case marking from occurring. It is maintained that the accusative case marker is the marker of direct-objecthood, so wherever it is used obligatorily, it serves the purpose of identifying the constituent it marks as the direct object. The additional pragmatic readings of specificity or definiteness arise within the parsing process as described in Sect. 4.1.

Reviewers also note that the proposed analysis incorrectly predicts that any argument can be unmarked in the IPV position; e.g. an indirect object might appear without the dative case marking in the IPV position without causing ungrammaticality. While the proposed analysis does not expressively preclude such instances, they are prohibited by other language-internal processes which are outside the scope of this paper. In an nutshell, a string where, as an example, an indirect object is not casemarked (in any sentential position) would be ruled out by the general principle of the Kazakh language, that all arguments must be marked (as outlined in Sect. 4.1), and that an indirect object must be marked by a dative case suffix at all times.

\section{Conclusions}

In this paper I have examined DOM in Kazakh from the perspective of the syntactic framework of DS which offers a parsing-oriented approach to the phenomenon. The main goal has been to demonstrate that accusative case is solely the marker of directobjecthood, and that the additional specificity/non-specificity readings, ascribed to marked and unmarked direct objects respectively, are pragmatic 'side effects' arising during the parsing process, and are not directly encoded into the case-markers or particular hierarchical positions.

It has been demonstrated that accusative case marking ensures that the element it marks is parsed onto a fixed node (as a direct object) before the parsing of the next item in the linguistic string begins. The lack of an accusative case marker indicates to the parser that the direct object at hand is to remain on an unfixed node until after 
the predicate is parsed. The contrast in these parsing strategies for one and the same syntactic constituent yields a contrast in their specificity, especially when a minimal pair of identical sentences is considered where the accusative case marker on the direct object is the only distinguishing element.

The DS formalism is further employed to explain that non-case-marked direct objects are restricted to the IPV position because it is the only position where an unmarked (and unfixed) direct object is guaranteed to obtain a fixed position at the next step of the parsing process. The proposed analysis of Kazakh DOM can be applied to DOM in Turkish and many other Turkic languages, and potentially, extended to non-related languages too; this is left for future research. ${ }^{11}$

Acknowledgements The author gratefully acknowledges the financial support from the Wolfson Foundation and the British Academy which made this research possible. I am thankful to all the Kazakh language consultants with whom I worked during my fieldwork in Kazakhstan in 2015 and 2016 for their generous help and patience. My special thanks are to the journal's two anonymous reviewers whose comments contributed greatly to the improvement of this paper. All errors and shortcomings remain mine.

Open Access This article is licensed under a Creative Commons Attribution 4.0 International License, which permits use, sharing, adaptation, distribution and reproduction in any medium or format, as long as you give appropriate credit to the original author(s) and the source, provide a link to the Creative Commons licence, and indicate if changes were made. The images or other third party material in this article are included in the article's Creative Commons licence, unless indicated otherwise in a credit line to the material. If material is not included in the article's Creative Commons licence and your intended use is not permitted by statutory regulation or exceeds the permitted use, you will need to obtain permission directly from the copyright holder. To view a copy of this licence, visit http://creativecommons.org/licen ses/by/4.0/.

\section{References}

Aydemir, Y. (2004). Are Turkish preverbal bare nouns syntactic arguments? LinguisticInquiry, 35, $465-474$.

Baker, M. (1988). Incorporation: A theory of grammatical function changing. . University of Chicago Press.

Balakaev, M. B. (1959). Sovremennyj Kazakhskij Jazyk - Sintaksis. [Modern Kazakh Language - Syntax]. . Izdatel'stvo Akademii.

Bossong, G. (1992). Zum Begriff des Subjekts in Sprachtypologie und Universalienforschung. In S. R. Anschütz (Ed.), Texte, Sätze, Wörter und Moneme. Festschrift für Klaus Heger zum Geburtstag. (pp. 105-122). Heidenberg: Orient.

Cann, R., \& Kempson, R. (2017). What do words do for us? Dialectica, 71(3), 425-460.

Cann, R., Kempson, R., \& Marten, L. (2005). The dynamics of language: An introduction. . Elsevier.

Cann, R., \& Miljan, M. (2012). Differential case-marking: Syntactic descriptions andpragmatic explanations. Linguistic Review, 29(4), 585-605.

Chatzikyriakidis, S. (2017). Afterthoughts in Greek. Journal of Linguistics, 53, 279-325.

\footnotetext{
11 A reviewer notes that Seraku and Gibson (2016) offer a similar analysis for analogous data from Japanese where many noun phrases can appear without a case marking immediately before a copula in cleft constructions. While the phenomena under consideration in this paper and in Seraku and Gibson's work are quite different, the observations concerning the position immediately before an item capable of projecting a full argument structure are strikingly similar. The analysis presented in this paper was arrived at independently from that by Seraku \& Gibson which, I believe, only strengthens both analyses and highlights the analytical power of the DS formalism.
} 
Christopher, N. (2018). Aspects of information structure of the Kazakh language-The Dynamic Syntax approach. Ph.D. SOAS, University of London.

Enç, M. (1991). The semantics of specificity. Linguistic Inquiry, 22, 1-25.

Erguvanlı, E. E. (1984). The function of word order in Turkish grammar. . University of California Press.

Gerdts, D. (1998). Incorporation. In A. Spencer \& A. M. Zwicky (Eds.), The handbook of morphology. (pp. 84-100). Blackwell.

Kempson, R., Meyer-Viol, W., \& Gabbay, D. (2001). Dynamic Syntax: The flow of language understanding. . Blackwell Publishers.

Kiaer, J. (2007). Processing and interfaces in syntactic theory: The case of Korean. . D. King's College London.

Kornfilt, J. (1984). Case marking, agreement, and empty categories in Turkish. . Harvard University.

Kornfilt, J. (1997). Turkish. . Routledge.

Kornfilt, J. (2003). Scrambling, subscrambling, and case in Turkish. In S. Karimi (Ed.), Word order and scrambling. (pp. 4-125). Blackwell.

Kornfilt, J. (2009). DOM and two types of DSM in Turkish. In H. de Hoop \& P. de Swart (Eds.), Differential subject marking. Springer.

Kuribayashi, Y. (1989). Accusative marking and noun-verb constructions in Turkish. Journal of the Linguistic Society of Japan, 95, 94-119.

Lewis, G. (1967). Turkish grammar. . Clarendon.

Marten, L. (2002). At the syntax-pragmatics interface: Verbal underspecification and concept formation in Dynamic Syntax. . Oxford University Press.

Mithun, M. (1984). The evolution of noun incorporation. Language, 60, 847-894.

Muhamedowa, R. (2016). Kazakh: A comprehensive grammar. . Routledge.

Orgun, C. O., \& Inkelas, S. (2004). Turkish direct objects: Incorporation or word order. CLS 40-1: The main session proceedings. (pp. 265-278). The Chicago Linguistic Society.

Seraku, T., \& Gibson, H. (2016). A Dynamic Syntax modelling of Japanese and Rangi clefts. Language Sciences, 56, 45-67.

Valiouli, M. (1994). Anaphora, agreement, and right dislocation in Greek. Journal of Semantics, 11, 55-82.

Van Geenhoven, V. (1998). Semantic incorporation and indefinite descriptions: Semantic and syntactic aspects of noun incorporation in West Greenlandic. . CSLI Publications.

von Heusinger, K. (2002). Specificity and definiteness in sentence and discourse structure. Journal of Semantics, 19, 245-274.

von Heusinger, K., \& Kornfilt, J. (2005). The case of the direct object in Turkish: Semantics, syntax and morphology. Turkic Languages, 9, 3-44.

Witzlack-Makarevich, A., \& Seržant, I. A. (2018). Differential argument marking: Patterns of variation. In I. A. Seržant \& A. Witzlack-Makarevich (Eds.), Diachrony of differential argument marking (Studies in diversity linguistics 19). (pp. 1-40). LanguageScience Press.

Publisher's Note Springer Nature remains neutral with regard to jurisdictional claims in published maps and institutional affiliations. 